\title{
End-Stage Renal Disease in the Gaza Strip and Its Relationship to Risk Factors
}

\author{
Hammoda Abu-Odah ${ }^{1}$, Yehia Abed ${ }^{2}$, Ali El-Khateeb ${ }^{3}$, Motasem Salah ${ }^{3}$ and Khawla El-Nems ${ }^{4}$ \\ 1. Department of Emergency, European Gaza Hospital, Rafah, Gaza Strip 00972, Palestine \\ 2. Department of Public Health, Al-Quds University, Gaza Strip 00972, Palestine \\ 3. Department of Health Profession, University Collage of Applied Sciences, Gaza Strip 00972, Palestine \\ 4. Department of Emergency, Al Karama Hospital, KhanYounis, Gaza Strip 00972, Palestine
}

\begin{abstract}
End Stage Renal Disease (ESRD) is an important cause of morbidity and mortality globally. Understanding the risk factors of ESRD can help identify preventive strategies. This study aimed to determine the risk factors of ESRD among patients undergoing hemodialysis in the governmental hospitals in Gaza Strip. Retrospective-hospital based-case control study was conducted on patients with ESRD, at Ministry of Health Hospitals at the time of study in $2014(N=264)$, proportional stratified random sample used for sample selection $(n=132)$ cases matched with sex, age, and locality to 132 control were chosen. Data was collected using a questionnaire including socio-demographic, medical history, and life style and additional data were obtained from medical record. The results showed that the most common risk factors associated with ESRD were hypertension (42.4\% versus $20.5 \%$ ) and diabetes mellitus (28\% versus $16.7 \%)$. Kidney stone (21.2\% versus $4.5 \%)$, urinary tract infection (65.9\% versus $27.3 \%)$ and glomerulonephritis (19.7\% versus $6.1 \%$ ) follow it. For medications analgesic drug formed among cases and controls (22\% versus $9.1 \%$ ). For smoking it was $(47.7 \%$ versus $23.5 \%)$, obesity $(41.7 \%$ versus $34.1 \%)$, anxiety $(17.4 \%$ versus $6.1 \%)$. For low activity $(48.5 \%$ versus $28 \%)$, primary educational level $(95.1 \%$ versus $39.4 \%$ ), low household income (76.5\% versus $59.1 \%$ ), family history $(70.5 \%$ versus $47.7 \%$ ). A multiple logistic regression controlling for age, gender, and location showed that significant predictors of ESRD were hypertension, glomerulonephritis, and obesity. In conclusion, the study suggests that most of the identified risk factors are preventable by easy ways as screening of highly risk people and encourage health life style.
\end{abstract}

Key words: End-stage renal disease, risk factors, haemodialysis, Gaza strip.

\section{Introduction}

End Stage Renal Disease (ESRD) is one of the serious kidney diseases that affect the body system [1]. It is a major health burden because not only it is progressive and irreversible, but also the patient with ESRD is increasing dramatically in the past few decades [2,3], in addition to diabetes mellitus and hypertension which consider as major risk factors to develop the disease [4]. The increasing of ESRD can lead to premature morbidity, mortality and lower quality of life.

ESRD occurs when both kidneys are no longer capable of working at the level of what is needed till it

Corresponding author: Hammoda Mohammed Abu-Odah, MPH., research field: public health. reaches the point where renal function fewer than $10 \%$ of standard [5]. It is a long-term problem caused by damage of both kidneys. The damage is usually irreversible and can lead to ill health [6]. It is a fatal condition unless supported by some form of dialysis, or kidney transplantation [7].

The situation is particularly serious in developing countries where smoking and other cardiovascular risk factors are increasing clearly [8, 9] and health information and health resource are limited. Palestine one of these countries will face the complications of this problem in the future, where the burden of this disease expected to exhaust its medical and financial system. The awareness of the risk factors of ESRD helps in developing programs and plan preventive measure for the community [10]. 
The current study aimed to characterize ESRD population in the Gaza strip and identify socio-demographic (e.g. age, sex), life style (e.g. smoking, physical activity) or comorbid disease (e.g. hypertension, diabetes) risk factors relevant to this population, in order to inform suggestions for strategies to reduce morbidity and mortality of patients.

\section{Research Methods}

\subsection{Design and Setting}

This was a retrospective hospital based case-control study that was conducted on ESRD patients treated at hospitals in the Gaza Strip. We collected data on eligible patients $(n=132)$ who were on hemodialysis at the time of study in 4-dialysis centers. Data collection was carried out between July 2014 and September 2014. Three months were spent at each of the 4-dialysis centers. Each patient was personally interviewed in the dialysis center using a structured questionnaire prepared by the researcher. The questionnaire collected comprehensive data related to ESRD patients. Relevant data for the present study included variables such as age and gender, living area, marital status, monthly income, diabetes mellitus, cardiovascular disease, family history of chronic disease and kidney stone, in addition to date of life style history as smoking, water, obesity and physical activity pattern.

\subsection{Sample}

The researcher used Epidemiological Information Program to calculate the sample size at $95 \%$ CI with power $80 \%$ and based on-one-to one case to control ratio. The total number of proportional stratified random samples is composed of 196 subjects. To overcome non-respondents, the researcher decided to take 264 persons, divided into 132 cases and 132 controls. A total of 264 cases and controls agreed to participate in this study.

\subsection{Data Collection}

The patients were interviewed by researcher to collect data related to socio-economic demographic variables such as age and gender, living area, marital status, monthly income, and other variables such as family history of chronic disease, diabetes mellitus, cardiovascular disease and kidney stone, in addition to date of life style history as smoking, water, obesity and physical activity pattern. Anthropometric measurements (weight and height), are essential as basic descriptive information in this study for calculating body mass index to all subjects for assessing the relationship between body mass index and developing ESRD. Body weight measured by Dual-Reading-Beam-Scale, accurate to $160 \mathrm{~kg}$ with subjects standing in the center of the platform, wearing only light clothes, weight distributed evenly to both feet and shoes off. The scale placed on a hard-floor surface and calibration should occur at the beginning and end of each examining subject. Height measured using Dual-Reading-Beam-Scale with subject stand with his heels together and the weight evenly distributed between both feet. BMI calculated as body weight $(\mathrm{kg})$ divided by squaring the height $\left(\mathrm{m}^{2}\right)$.

\subsection{Data Management and Statistical Analysis}

The quantitative data were analyzed using Statistical Package for Social Sciences (SPSS) program version 19.0. The analyses of data to be conducted were reviewing the filled questionnaire, coding the questions, data entry, defining and coding the variables, and data cleaning. Frequency tables of all the variables and cross tabulation of the results were done. Differences between means were analyzed using independent sample $t$-test, Odds ratio, 95\% confidence interval, and chi-square test is statistical tool of measurement of association. A $P$-value $\leq 0.05$ is considered statistically significant. Logistic regression used to control for a confounder.

\subsection{Ethical and Administrative Considerations}

An academic Approval was obtained from School of Public Health at Al-Quds University, and an ethical 
approval was obtained from Helsinki Committee in Gaza to carry out the study. An administrative approval was obtained from Ministry of Health-Gaza to conduct the study at four hospitals. Every participant was provided with a full explanatory form attached to questionnaire included the purpose of the study, assurance about the confidentiality of the information, the instructions how to respond to the questionnaire, and a statement indicating that the participation is voluntary. Honesty was maintained during reporting and analysis of the data with respect to confidentiality and respecting of results

\section{Results}

\subsection{Socio-demographic Characteristics}

Table 1 shows that the prevalence of males among the cases was $56.8 \%$ and $38.6 \%$ of them were in the age range 45-60 years. The highest prevalence was found in Gaza city (28.6\%) and the lowest percentage was in Mid-zone (15.2\%). This distribution is corresponding to the population differences in the Governorates, where one-third of the population is living in Gaza city.

The prevalence of ESRD was higher in low educational level with $59.1 \%$ among cases and only

Table 1 Socio-demographic characteristics of the study participants.

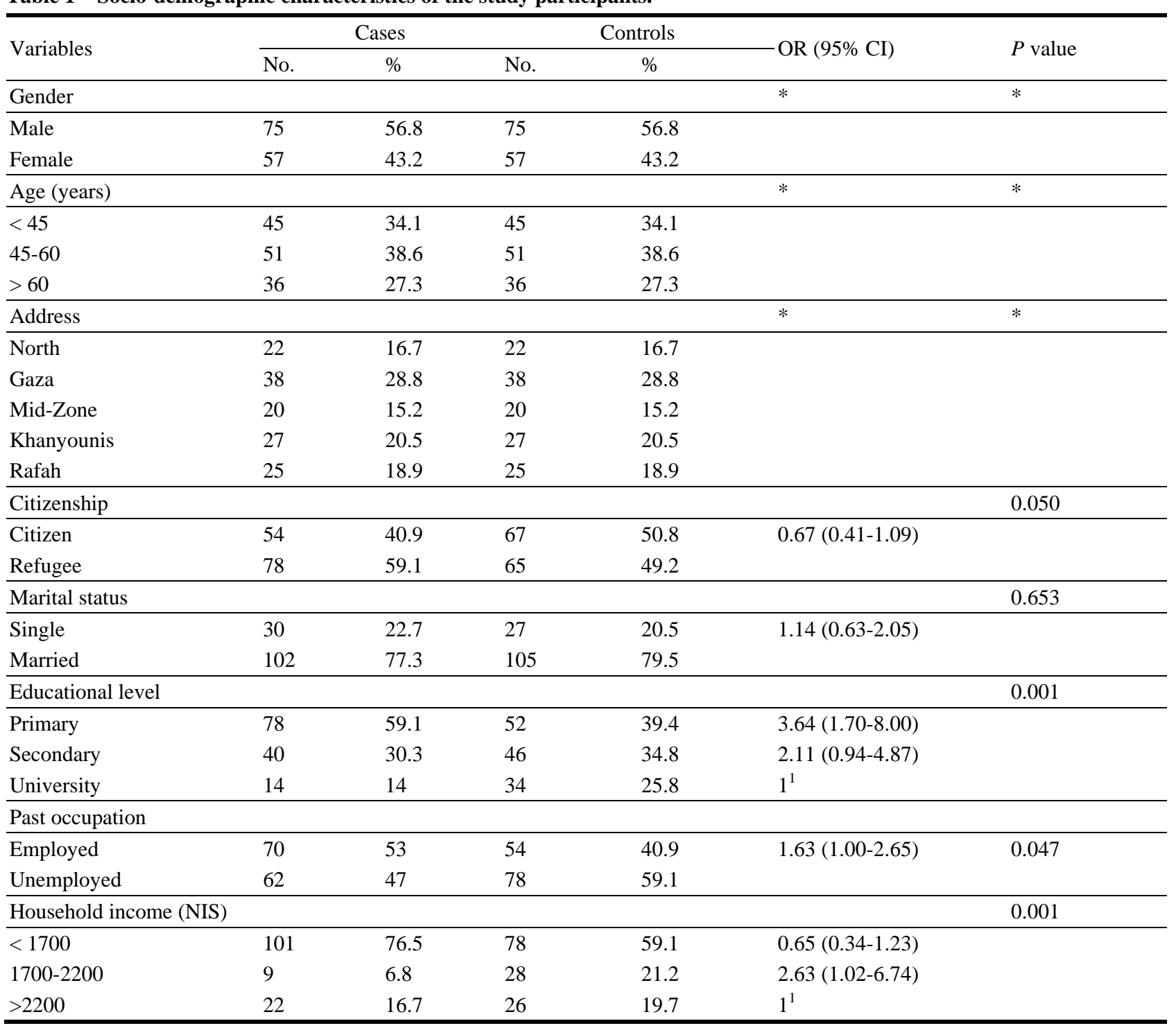

* Matched variables, $1{ }^{1}$ Referenced factor. 
$39.4 \%$ among controls. The difference between low and high education is statistically significant with $\mathrm{OR}=$ 3.64 (1.70-8.00). Employed subject was 53\% among cases and $40.9 \%$ among controls with $\mathrm{OR}=1.630$ (1.002-2.654). The burden of end-stage renal disease was insignificantly lower among single subjects OR = 1.143 (0.635-2.057). The present study showed highest risk of end-stage renal disease among subjects with highest poverty rate with $76.5 \%$ among cases compared to $59.1 \%$ among controls with statistical significant differences $\mathrm{OR}=2.632$ (1.026-6.749).

\subsection{Medical History}

Table 2 shows that the prevalence of Cardiovascular Disease (CVD) and diabetes mellitus among end-stage renal disease was higher $(51.5 \%, 28.0 \%$ respectively) than among controls and the association reaches statistically significant level $(\mathrm{OR}=4.13$ versus 1.94$)$. Hypertension represents the most CVD (42.4\%) compared to controls $(20.5 \%)$. This association reaches statistically significant level $(\mathrm{OR}=0.67)$. Type II diabetes was the prominent among cases than type I $(26.5 \%)$ and $(18.9 \%)$ treated with insulin for more than ten years.

The prevalence of lung diseases among end-stage renal disease was higher $(13.6 \%, 2.3 \%$ respectively) than among controls and the association reach statistically significant level $(\mathrm{OR}=6.78)$. Most of them suffer from bronchitis $(9.1 \%)$. For kidney diseases, end-stage renal disease was significantly higher in

Table 2 Medical history among the study participants.

\begin{tabular}{|c|c|c|c|c|c|c|}
\hline \multirow{2}{*}{ Variables } & \multicolumn{2}{|c|}{ Cases } & \multicolumn{2}{|c|}{ Controls } & \multirow{2}{*}{ OR $(95 \% \mathrm{CI})$} & \multirow{2}{*}{$P$ value } \\
\hline & No. & $\%$ & No. & $\%$ & & \\
\hline CVA & & & & & & 0.000 \\
\hline Yes & 68 & 51.5 & 27 & 20.5 & $4.13(2.40-7.11)$ & \\
\hline No & 64 & 48.5 & 105 & 79.5 & & \\
\hline Type of CVA & & & & & & 0.020 \\
\hline HTN & 56 & 42.4 & 27 & 20.5 & $0.67(0.58-0.78)$ & \\
\hline Non-HTN & 12 & 9.1 & 0 & 0 & & \\
\hline DM & & & & & & 0.027 \\
\hline Yes & 37 & 28 & 22 & 16.7 & $1.94(1.07-3.53)$ & \\
\hline No & 95 & 72 & 110 & 83.3 & & \\
\hline Lung diseases & & & & & & 0.000 \\
\hline Yes & 18 & 13.6 & 3 & 2.3 & $6.78(1.94-23.6)$ & \\
\hline No & 114 & 86.4 & 129 & 97.7 & & \\
\hline Kidney stones & & & & & & 0.000 \\
\hline Yes & 28 & 21.2 & 6 & 4.5 & $5.65(2.25-14.1)$ & \\
\hline No & 104 & 78.8 & 126 & 95.5 & & \\
\hline Urinary Tract Infection & & & & & & 0.000 \\
\hline Yes & 87 & 65.9 & 36 & 27.3 & $5.15(3.04-8.72)$ & \\
\hline No & 45 & 34.1 & 96 & 72.7 & & \\
\hline Glomerulonephritis & & & & & & 0.000 \\
\hline Yes & 26 & 19.7 & 8 & 6.1 & $3.80(1.56-9.59)$ & \\
\hline No & 106 & 80.3 & 124 & 93.3 & & \\
\hline Analgesic drug & & & & & & 0.003 \\
\hline Yes & 29 & 22 & 12 & 9.1 & $2.18(1.36-5.79)$ & \\
\hline No & 103 & 78 & 120 & 90.9 & & \\
\hline Family history & & & & & & 0.000 \\
\hline Positive & 93 & 70.5 & 63 & 47.7 & $2.52(1.52-4.17)$ & \\
\hline Negative & 39 & 30.5 & 69 & 52.3 & & \\
\hline
\end{tabular}


subjects with kidney stones $(\mathrm{OR}=5.65)$, urinary tract infection $(\mathrm{OR}=5.15)$, and glomerulonephritis $(\mathrm{OR}=$ 3.80). Regarding analgesic drug, the prevalence among cases was higher than controls (22.0 versus $9.1 \%)$. and the association reach statistically significant level (OR $=2.18)$. The prevalence of positive family history among end-stage renal disease was higher $(70.5 \%$, $47.7 \%$ respectively) than among controls and the association reach statistically significant level (OR = $2.52)$, most of them have family history to DM (25\%), followed by HTN (14.3\%), end-stage renal disease $(6.1 \%)$.

\subsection{Life Style Factors}

ESRD was significantly higher in subjects who were smoking, former smoking, obese, exposed to psychological troubles and physically inactive persons. Low activity is much higher among cases (48.5\%) compared to controls (28\%). This association reached statistically significant level. End-stage renal disease is positively associated with the current smoking status where the prevalence of current smoking among cases (17.5\%) was higher compared to controls (8.4\%). ESRD patients who former smoking was much two time among cases than controls $(30.3 \%, 15.1 \%$ respectively) and reach positively significant level (OR $=2.43)$. There was negative association between exposed to other form of smoking and end-stage renal disease occurrence, which the prevalence among controls was higher than cases $(67.5 \%$ versus $52.2 \%)$. Concerning body mass index, the prevalence was significantly higher in cases than controls $(\mathrm{OR}=1.60)$, and with psychological troubles $(\mathrm{OR}=4.03)$.

\subsection{Logistic Regression}

Table 4 demonstrates logistic regression analysis for the ESRD risk factors. Significant ESRD predictors as revealed by multivariate logistic regression analysis included CVD, glomerulonephritis, and high BMI remained associated with ESRD, and reached statistically significant level. The association between ESRD and physical inactivity, smoking group, past

Table 3 Life style factors among the study participants.

\begin{tabular}{|c|c|c|c|c|c|c|}
\hline \multirow{2}{*}{ Variables } & \multicolumn{2}{|c|}{ Cases } & \multicolumn{2}{|c|}{ Controls } & \multirow{2}{*}{ OR $(95 \% \mathrm{CI})$} & \multirow{2}{*}{$P$ value } \\
\hline & No. & $\%$ & No. & $\%$ & & \\
\hline Current smoking & & & & & & 0.027 \\
\hline Yes & 23 & 17.5 & 11 & 8.4 & & \\
\hline No & 109 & 82.5 & 121 & 91.6 & & \\
\hline Former smoker & & & & & & 0.003 \\
\hline Yes & 40 & 30.3 & 20 & 15.1 & $2.43(1.33-4.45)$ & \\
\hline No & 92 & 69.7 & 112 & 84.2 & & \\
\hline Exposed to other smokes & & & & & & 0.000 \\
\hline Yes & 69 & 52.2 & 101 & 76.5 & $0.33(0.19-0.56)$ & \\
\hline No & 63 & 47.8 & 31 & 23.5 & & \\
\hline BMI level & & & & & & 0.000 \\
\hline $\mathrm{BMI} \geq 30 \mathrm{~kg} / \mathrm{m}$ & 69 & 52.3 & 23 & 47.4 & $1.60(4.21-13.7)$ & \\
\hline $\mathrm{BMI} \leq 30 \mathrm{~kg} / \mathrm{m}$ & 43 & 17.5 & 109 & 82.5 & & \\
\hline \multicolumn{7}{|l|}{ Physical activity level } \\
\hline Physically & 33 & 25 & 36 & 27.3 & $1^{1}$ & \\
\hline Sedentary & 10 & 7.6 & 4 & 3 & $0.36(0.10-1.28)$ & 0.111 \\
\hline Low active & 64 & 48.5 & 37 & 28 & $0.53(0.28-0.98)$ & 0.045 \\
\hline Very active & 25 & 18.9 & 55 & 41.7 & $2.01(1.03-3.93)$ & 0.040 \\
\hline Psychological troubles & & & & & & 0.000 \\
\hline Yes & 45 & 34.1 & 15 & 11.4 & $4.03(2.11-7.70)$ & \\
\hline No & 65.9 & 65.9 & 117 & 88.6 & & \\
\hline
\end{tabular}


Table 4 Logistic regression for ESRD risk factors.

\begin{tabular}{llllllll}
\hline Variables & B & S.E & Wald & Sig. & Exp(B) & \multicolumn{2}{c}{ 95\% C.I for OR } \\
\cline { 6 - 8 } & & & & & & Lower & Upper \\
CVA & 3.75 & 0.83 & 20.14 & 0.000 & 42.50 & 8.26 & 218.5 \\
Glomerulonephritis & 3.26 & 0.89 & 13.28 & 0.000 & 26.19 & 4.52 & 151.5 \\
BMI group & 1.83 & 0.46 & 8.87 & 0.003 & 3.99 & 1.60 & 9.944 \\
Physical inactivity & 0.44 & 0.27 & 2.57 & 0.109 & 1.56 & 0.90 & 2.692 \\
Smoking group & 0.41 & 0.35 & 1.35 & 0.24 & 1.51 & 0.75 & 3.033 \\
Past occupation & 0.19 & 0.30 & 0.42 & 0.51 & 1.21 & 0.67 & 2.208 \\
Education & 0.44 & 0.49 & 0.82 & 0.36 & 1.56 & 0.59 & 4.089 \\
Constant & -20.1 & 4.02 & 25.08 & 0.000 & & & \\
\hline
\end{tabular}

occupations, and educational group did not reach statistically significant level.

\section{Discussion}

The study result revealed that the prevalence of ESRD was higher in men than women, this result matched with national and international studies showed that men had significantly higher rate of end-stage renal disease compared with women [11-15]. In contrast to this, women seem to develop end-stage renal disease most often than men [16]. It also revealed that age group between 45-60 years is a higher risk for developing end-stage renal disease; this finding coincident with other studies showed that the prevalence of chronic renal disease increases with age $[13,17-19]$. Most of end-stage renal disease patient is refugees and settle in Gaza city, this settle is corresponding to the population differences in the Governorates, where Gaza city is the highest population density with average $13.2 \%$ of the total population [20] and $67 \%$ of them are refugees [21]. The researchers concluded that being refugees could be increased the risk of end-stage renal disease. This may be due to siege; bad socioeconomic, epidemiological transitions in Palestine, as well as transitions in food consumption patterns and lifestyle have aggravated the burden of poverty-related diseases, as people are suffering from emerging epidemics of NCDs. The prevalence of end-stage renal disease was higher in low educational level; this result corresponded with other studies showed low educational level considered a risk for chronic kidney diseases [22, 23]. The present study showed highest risk of ESRD among subjects who lived under poverty line with significant relationship between renal disease and subject's monthly income; these results reflect a poor economic situation was higher among cases, this significant may related to other factors affect it, for example, Palestine is usually unstable because of policies of closure and siege and shelling and destruction perpetrated by Israel. Unstable economic situation, limited income, and lack of unemployment opportunities, all of these reasons lead to drop in standard living and increased poverty, which has a negative effect on health [24]. This statement agrees with study result that confirms low household income is a risk factor for developing ESRD. Another study agrees this statement, for example, Ward, performed studies to examine the association between socioeconomic status with increased risk of ESRD due to diabetes and access to care in California, reported that there is a strong association between the incidence of ESRD related to diabetes and access to care [25]. Other studies confirm that positive relation between living in low socioeconomic status and severity of chronic renal disease [17, 26]. This study found statistical significant association between occupation, primary educational level, low income, and citizenship subjects tended to have significantly higher end-stage renal disease prevalence.

This study also revealed that, $68 \%$ of ESRD patients have history of CVD; Hypertension considered the main risk factor that represents $42.4 \%$ of the cases. Average duration of CVD in years among cases was higher than among controls (13.7-8.4 respectively); 
this means that uncontrolled blood pressure seriously increased the risk of developing end-stage renal disease. The study results agreed with previous studies that hypertension considered a risk factor leads to end-stage renal disease. Abumwais revealed that the three most common causes of chronic kidney disease were diabetes, hypertension and glomerulonephritis $(33.32 \%, 16.7 \%$ and $13.1 \%)$ respectively [27]. Basheer demonstrated that diabetes, hypertension, cardiovascular disease, recurrent taken analgesic drug and urinary tract infection are major risk factors that significantly associated with the onset of the ESRD [28]. Additionally, Elsharif, M. and Elsharif, E, reported that hypertension and obstructive nephropathy are the leading causes of end-stage renal disease in Gazira state [12]. Moreover, Sweileh et al. conducted study in A-Watani governmental medical center; show that hypertension and diabetes were the most common causes of the end-stage renal disease [29]. Although, Domrongkitchaiporn et al. shows that HTN was the most important independent risk factor for future development of kidney disease [30]. Similarly, Hsu et al. concluded that the risk of end-stage renal disease is increased even with relative modest elevations of blood pressure [31]. Finally, many studies informed that hypertension is a risk factor for chronic kidney disease [32-35]. In contrast to that, Fesler et al. informed association between hypertension and chronic kidney disease did not reach statistical significance [36] and Bakris and Ritz, indicated that hypertension is the second most common cause of end-stage renal disease [37]. The study also, identified common risk factors in this study was diabetes mellitus with prevalence was $28 \%$ among cases. This funding agreed with the results that diabetes mellitus is a risk factor. Abumwais, revealed that the three most common causes of Chronic Renal Failure (CRF) were diabetes mellitus, hypertension and glomerulonephritis $(33.32 \%, 16.7 \%$ and $13.1 \%$ ) respectively [27]. Although, a retrospective cohort study conducted in A-Watani governmental medical center in Palestine; show that hypertension and diabetes mellitus were the most common causes of the ESRD [29]. Additionally, Shaheen and Al-Khader, detailed that diabetes mellitus is still the most common cause of ESRD in Egypt, Kuwait, Lebanon and Saudi Arabia [38]. Similarly, Malekmakan et al. stated that the risk factors of chronic renal disease according to the age, hypertension $(30.5 \%)$ and diabetes mellitus $(30.1 \%)$ were the most common causes of end-stage renal disease [4]. Another study agrees with this result, conducted at a Mostafa Khomini hospital in Iran, showed that the prevalence of chronic renal disease is higher in Iran and the most common risk factor is diabetes mellitus $26.85 \%$ [13]. In Jordan, a study conducted by Abdullah et al. confirms that diabetes mellitus was the major leading cause of end-stage renal disease $29.2 \%$ of cases [39]. In contrast to study positive association, Chadban et al. conducted a large cross-sectional Australian cohort study, stated that there is no association between diabetes mellitus and the presence of chronic kidney diseases [35]. This study identified another risk factor was lung diseases with a positive history of lung disease among ESRD. It is congruent with Daggett who found abnormalities of glomerular filtration rate among chronic bronchitis patients [40]. Moreover, it indicates that kidney stone is considered as another risk factor for developing ESRD. This result agreed with international studies that found that nephrolithiasis is still another risk factor that develop end-stage renal disease [41, 42].

There is positive association between subject's history of glomerulonephritis and the occurrence of end-stage renal disease. This finding is in agreement with other national and international studies, that found urinary tract infection and glomerulonephritis are major risk factors that significantly associated with the onset of ESRD [4, 11, 12, 27, 28, 32, 39].

Family history is considered as another risk factor for developing ESRD in this study. This funding agreed with the results that family history is a risk factor. McClellan, et al. showed that the first- or second-degree family members of patients with 
end-stage renal disease have two to three times as likely to have incident end-stage renal disease [43]. Additionally, as a population-based telephone survey conducted in the southeastern state of 402 residents showed that a family history of ESRD was reported by $3.7 \%$ of respondents and that black residents were six times more likely to develop family history end-stage renal disease compared with white individuals [44]. The prevalence of taking an analgesic drug 20.5\% among cases take diclofen while $1.5 \%$ takes Trufen was higher and association reaches significant level. This result is consistent with literature. Perneger et al. confirmed that frequently taken analgesic drugs (acetaminophen or none steroidal Anti-inflammatory Drugs) have an increased risk of ESRD, aspirin is excluded from this study [45].

Active smoking is divided into two categories as shows above, $30.3 \%$ former smoker while $17.4 \%$ smoker. The average of cigarette smoking per day among cases was higher than among controls (1.26-1.18 respectively) and the association does not reach statistically significance ( $P$ value 0.39$)$. In addition, the average duration of smoking per years among cases was higher than controls (1.18-1.09 respectively) and the association does not reach statistically significance ( $P$ value 0.23$)$. This is consistent with the studies revealed that cigarette smoking is considered as a risk factor for developing and progressing of chronic kidney disease in the community [46, 47]. Moreover, Yacoub et al. concluded that the risk of chronic renal disease increased significantly with smoking when comparing to non-smoker, and there is no statistically significant difference between former smoker and chronic renal disease and this study found that heavy smoking more than 30 packs per year is an important risk factor for developing chronic renal disease [48]. Moreover, Chadban et al. confirm the association between smoking and renal damage [35]. On the other hand, population base case control study showed that there was strong association between heavy smoking and chronic renal disease [49]. Concerning obesity as a risk factor, the study showed that $41.7 \%$ of end-stage renal disease was obese, while $34.1 \%$ among controls were obese. This reflected the increase of obesity in the Palestinian population as a result of lifestyle shifting toward physical inactivity and increased food consumption. We noted that there was strong association between ESRD and obesity ( $P$ value 0.000$)$ indicating that obesity is a risk factor of ESRD. These results agree with international studies that conducted in Japan, California, and Singapore which showed that there are strong positive association between body mass index and the risk of developing ESRD [17, 50-52], but inconsistent with Pinto-Sietsma et al. who reported body mass index had no effect on the prevalence of chronic kidney disease [53].

The study also identified psychological troubles as risk factors with prevalence (34.1\%) among cases. Among them, $17.4 \%$ facing anxiety followed by depression $14.4 \%$. This funding agreed with the results that psychological trouble is a risk factor. DiMatteo et al. identified that the two common psychiatric symptoms in medical patients are depression and anxiety; and it is also associated with deteriorated health status and increased health care utilization [54]. Moreover, Lew and Patel found that in ESRD population, women are more common and at a higher level than men for expressing psychological problem such as depression, anxiety and personality disorder [55]. Similarly, Kimmel stated that the most prevalent psychiatric problem among patients undergoing hemodialysis is depression [56, 57].

\section{Conclusion}

ESRD is one of the serious kidney diseases of chronic renal disease that affect the body system. Identification of risk factors for end stage renal disease supports intervention policies to minimize the disease morbidity and mortality. This disease is serious in Palestine, mostly GS and it is apparent as chronic disease, dangerous and leading to death. Chronic 
diseases are responsible for $81 \%$ of the total deaths in Palestine. The general objective of this study is to identify the main risk factors that contribute to the ESRD among hemodialysis patients in GS. This study gets its importance because there is no study examines the risk factors associated with end-stage renal disease in GS. This study might enhance national effort to modify and control of those factors and help in developing preventive promotional and educational health programs. Also it help for developing screening programs of people at high risk of renal disease, and all patients with diabetes or and have hypertension. Moreover, preventive strategies to integrate health life style into the community approach to primary prevention should start early to change bad habits to good behaviour as encourage walking, playing and bicycling, improve physical activity level, and put strict laws by the relevant ministries to prevent smoking in public places and then private places, especially at home. Additionally, this study might increase awareness about renal disease among the clients with the identified risk factors in order to decrease morbidity and mortality from this disease.

\section{Acknowledgement}

Firstly, the authors would like to thank Allah during the study. The authors thank all participating men and women whose efforts enabled this study. The authors are indebted to the physicians who care for patients undergoing haemodialysis in Palestine for participation, to staff nurses who deals gently and melodic with patients and to all people that have contributed to the completion of this research.

\section{References}

[1] National Institute of Health and Clinical Excellence. 2008. "Chronic Kidney Disease CG 73: Early Identification and Management of Chronic Kidney Disease in Adults in Primary and Secondary Care." NICE guidelines [CG73].

[2] Kirby, T. 2010. "Screening for Chronic Kidney Disease Shows Promise." The Lancet 375 (9722): 1240-1.

[3] Orth, R. S., and Hallan, I. S., 2008. "Smoking: A Risk Factor for Progression of Chronic Kidney Disease and for
Cardiovascular Morbidity and Mortality in Renal Patients-Absence of Evidence or Evidence of Absence?" American Society of Nephrology 3 (1): 226-36.

[4] Malekmakan, L., Haghpanah, S., Pakfetrat, M., Malekmakan, A., and Khajehdehi, P. 2009. "Causes of Chronic Renal Failure among Iranian Hemodialysis Patients." Saudi Journal of Kidney Diseases and Transplantation 20 (3): 501-4.

[5] European Kidney Patients Federation. 2006. Treatment of End Stage Renal Disease from the Patient's Perspective.

[6] Scottish Intercollegiate Guidelines Network. 2008. Diagnosis and Management of Chronic Kidney Disease-A National Clinical Guideline.

[7] Johannsson, G., and Ahlmén, H. 2003. "End-stage Renal Disease: Endocrine Aspects of Treatment." Growth Hormone \& IGF Research 13 (Suppl A): 94-101.

[8] Kiberd, B. 2006. "The Chronic Kidney Disease Epidemic: Stepping Back and Looking Forward." Journal of the American Society of Nephrology 17 (11): 2967-73.

[9] White, S. L., Cass, A., Atkins, R. C., and Chadban, S. J. 2005. "Chronic Kidney Disease in the General Population." Advances in Chronic Kidney Disease 12 (1): 5-13.

[10] Ministry of Health. 2011. Hospital annual report. Gaza Strip, Palestine.

[11] El-Minshawy, Q. 2011. "End Stage Renal Disease in El-Minia Governorate, Egypt: Data of the Year 2007." Nephro-Urol. Mon. 3 (2): 118-21.

[12] Elsharif, E. M., and Elsharif, G. E., 2011. "Causes of End-stage Renal Disease in Sudan: A Single-center Experience." Saudi Journal of Kidney Diseases and Transplantation 22 (2): 373-6.

[13] Afshar, R., Sanavi, S., and Salimi, J. 2007. "Epidemiology of Chronic Renal Failure in Iran: A Four Year Single Center Experience." Saudi Journal of Kidney Diseases and Transplantation 18 (2): 191-4.

[14] Nagata, M., Ninomiya, T., Doi, Y., Yonemoto, K., Kubo, M., Hata, J., Tsuruya, K., Iida, M., and Kiyohara, Y. 2010. "Trends in the Prevalence of Chronic Kidney Disease and Its Risk Factors in a General Japanese Population: The Hisayama Study." Nephrology Dialysis Transplantation 5 (25): 342-252.

[15] Silbiger, S., and Neugarten, J. 2008. "Gender and Human Chronic Renal Disease." Gender Medicine 5 (Suppl A): 3-10.

[16] Centers for Disease Control and Prevention (CDC). 2010. National Chronic Kidney Disease Fact Sheet.

[17] Hsu, C. Y., McCulloch, C. E., Iribarren, C., Darbinian, J., and Go, A. S. 2006. "Body Mass Index and Risk for End-stage Renal Disease." Annals of Internal Medicine 144 (1): 21-9.

[18] Pavkov, M. E., Bennett, P. H., Knowler, W. C., Krakoff, 
J., Sievers, M. L., and Nelson, R. G. 2006. "Effect of Youth-onset Type 2 Diabetes Mellitus on Incidence of END-stage Renal Disease and Mortality in Young and Middle-aged Pima Indians." The Journal of the America Medical Association 296 (4): 421-6.

[19] Yu, M., Ryu, D. R., Kim. S. J., Choi, K. B., and Kang, D. H. 2010. "Clinical Implication of Metabolic Syndrome on Chronic Kidney Disease Depends on Gender and Menopausal Status: Results from the Korean National Health and Nutrition Examination Survey." Nephrology Dialysis Transplantation 2 (25): 469-77.

[20] Palestinian Central Bureau of Statistics (PCBS). 2010. Population, Hosing and Establishment Census, Palestine.

[21] Ministry of Health. 2010. Population and health annual report 2010. Gaza Strip, Palestine.

[22] Fored, C. M., Ejerblad, E., Fryzek, J. P., Lambe, M., Lindblad, P., Nyrén, O., and Elinder, C. G. 2003. "Socio-economic Status and Chronic Renal Failure: A Population-based Case-control Study in Sweden." Nephrology Dialysis Transplantation 18 (1): 82-8.

[23] Hsu, C. C., Hwang, S. J., Wen, C. P., Chang, H. Y., Chen, T., Shiu, R. S., Horng, S. S., Chang, Y. K., and Yang, W. C. 2006. "High Prevalence and Low Awareness of CKD in Taiwan: A Study on the Relationship between Serum Creatinine and Awareness from a Nationally Representative Survey." American Journal of Kidney Diseases 48 (5): 727-38.

[24] Ministry of Health. 2012. Health Determinants. Gaza Strip, Palestine.

[25] Ward, M. M. 2009. "Access to Care and the Incidence of End-stage Renal Disease Due to Diabetes." DIABETES CARE 32 (6): 1032-6.

[26] Bello, A. K., Peters, J., Rigby, J., Rahman, A. A., and El Nahas, M. 2008. "Socioeconomic Status and Chronic Kidney Disease at Presentation to a Renal Service in the United Kingdom." Clinical Journal of the American Society of Nephrology 3 (5): 1316-23.

[27] Abumwais, J. Q. 2012. "Etiology of Chronic Renal Failure in Jenin District, Palestine." Saudi Journal of Kidney Diseases and Transplantation 23 (1): 158-61.

[28] Basheer, K. N. 2011. "Major Risk Factors that Lead to Onset End-stage Renal Disease in Northern West Bank." Unpublished thesis. An-Najah National University, Palestine.

[29] Sweileh, W. M., Sawalha, A. F., Zyoud, S. H., Al-Jabi, S. W., and Shraim, N. Y. 2009. "Prevalence of Reduced Renal Function among Diabetic Hypertensive Patients." International Journal Physiology Pathphysiology Pharmacology 1 (1): 41-7.

[30] Domrongkitchaiporn, S., Sritara, P., Kitiyakara, C., Stitchantrakul, W., Krittaphol, V., Lolekha, P., Cheepudomwit, S., and Yipintsoi, T. 2005. "Risk Factors for Development of Decreased Kidney Function in a Southeast Asian Population: A 12-year Cohort Study." Journal of the American Society of Nephrology 16 (3): 791-9.

[31] Hsu, C. Y., McCulloch, C. E., Darbinian, J., Go, A. S., and Iribarren, C. 2005. "Elevated Blood Pressure and Risk of End-stage Renal Disease in Subjects without Baseline Kidney Disease." Archive Internal Medicine 165 (8): 923-8.

[32] Foley, R. N., Murray, A. M., Li, S., Herzog, C. A., McBean, A. M., Eggers, P. W., and Collins, A. J. 2005. "Chronic Kidney Disease and the Risk for Cardiovascular Disease, Renal Replacement, and Death in the United States Medicare Population, 1998 to 1999." Journal of the American Society of Nephrology 16 (2): 489-95.

[33] Fox, C. S., Larson, M. G., Leip, E. P., Culleton, B., Wilson, P. W., and Levy, D. 2004. "Predictors of New-onset Kidney Disease in a Community-based Population." The Journal of the American Medical Association 291 (7): 844-50.

[34] Coresh, J., Astor, B. C., Greene, T., Eknoyan, G., and Levey, A. S. 2003. "Prevalence of Chronic Kidney Disease and Decreased Kidney Function in the Adult US Population: Third National Health and Nutrition Examination Survey." American Journal of Kidney Diseases 41 (1): 1-12.

[35] Chadban, S. J., Briganti, E. M., Kerr, P. G., Dunstan, D. W., Welborn, T. A., Zimmet, P. Z., and Atkins, R. C. 2003. "Prevalence of Kidney Damage in Australian Adults. The AusDiab Kidney Study." Journal of the American Society of Nephrology 14 (7): 131-8.

[36] Fesler, P., Ribstein, J., du Cailar, G., and Mimran, A. 2005. "Determinants of Cardiorenal Damage Rogression in Normotensive and Never-treated Hypertensive Subjects." Kidney International 56 (5): 1974-9.

[37] Bakris, G. L., and Ritz, E. 2009. "The Message for World Kidney Day 2009. Hypertension and Kidney Disease: A Marriage that Should Be Prevented." Nephrology Dial Transplant 24 (3): 695-7.

[38] Shaheen, F., and Al-Khader, A. 2005. "Preventive Strategies of Renal Failure in the Arab World." Kidney International Supplements 68 (98): 37-40.

[39] Abdallah, S., Ahmad, A. T., Batieha, A., and Ajlouni, K. 2007. "Diabetes Mellitus: The Leading Cause of Haemodialysis in Jordan." Eastern Mediterranean Health Journal 13 (4): 803-9.

[40] Daggett, P. 1997. "An Investigation of Renal Function in Chronic Bronchitis.” Postgraduate Medical Journal 53 (615): 24-7.

[41] Ounissi, M., Gargueh, T., Mahfoudhi, M., Boubaker, K., Hedri, H., Goucha, R., Abderrahim, E., Ben Hamida, F., Ben Abdallah, T., El Younsi, F., Ben Maiz, H., and Kheder, 
A. 2010. "Nephrolithiasis-induced End Stage Renal Disease." International Journal of Nephrology and Reno Vascular Disease 2010 (3): 21-6.

[42] Saucier, N. A., Sinha, M. K., Liang, K. V., Krambeck, A. E., Weaver, A. L., Bergstralh, E. J., Li, X., Rule, A. D., and Lieske, J. C. 2010. "Risk Factors for Chronic Kidney Disease in Persons with Kidney Stones: Case-control Study in Olmsted County, Minnesota." American Journal of Kidney Diseases 55 (1): 61-8.

[43] McClellan, W. M., Satko, S. G., Gladstone, E., Krisher, J. O., Narva, A. S., and Freedman, B. I. 2009. "Individuals with a Family History of ESRD Are a High-risk Population for CKD: Implications for Targeted Surveillance and Intervention Activities." American Journal of Kidney Diseases 53 (3): 100-6.

[44] Jurkovitz, C., Hylton, T. N., and McClellan, W. M. 2005. "Prevalence of Family History of Kidney Disease and Perception of Risk for Kidney Disease: A Population-based Study." American Journal of Kidney Diseases 46 (1): 11-7.

[45] Perneger, T. V., Whelton, P. K., and Klag, M. J. 1994. "Risk of Kidney Failure Associated with the Use of Acetaminophen, Aspirin, and Nonsteroidal Anti-inflammatory Drugs." The New England Journal of Medicine 25 (331): 1675-9.

[46] Bleyer, A. J., Shemanski, L. R., Burke, G. L., Hansen, K. J., and Appel, R. G. 2000. "Tobacco, Hypertension, and Vascular Disease: Risk Factors for Renal Functional Decline in an Older Population." Kidney International 57 (5): 2072-9.

[47] Yamagata, K., Ishida, K., Sairenchi, T., Takahashi, H., Ohba, S., Shiigai, T., Narita, M., and Koyama. A. 2007. "Risk Factors for Chronic Kidney Disease in a Community-based Population: A 10-year Follow-up Study." Kidney Int. 71 (2): 159-66.

[48] Yacoub, R., Habib, H., Lahdo, A., Al Ali, R., Varjabedian, L., Atalla, G., Kassis Akl, N., Aldakheel, S., Alahdab, S., and Albitar, S. 2010. "Association between Smoking and Chronic Kidney Disease: A Case Control Study." BMC Public Health 25 (10): 1-6.
[49] Ejerblad, E., Fored, C. M., Lindblad, P., Fryzek, J., Dickman, P. W., Elinder, C. G., McLaughlin, J. K., and Nyrén, O. 2004. "Association between Smoking and Chronic Renal Failure in a Nationwide Population-based Case-control Study." Journal of the American Society of Nephrology 15 (8): 2178-85.

[50] Nomura, I., Kato, J., and Kitamura, K. 2009. “Association between Body Mass Index and Chronic Kidney Disease: A Population-based, Cross-sectional Study of a Japanese Community." Vascular Health and Risk Management 5 (1): 315-20.

[51] Shankar, A., Leng, C., Chia, K. S., Koh, D., Tai, E. S., Saw, S. M., Lim, S. C., and Wong, T. Y. 2008. "Association between Body Mass Index and Chronic Kidney Disease in Men and Women: Population-based Study of Malay Adults in Singapore." Nephrology Dialysis Transplantation 23 (6): 1910-8.

[52] Tozawa, M., Iseki, K., Iseki, C., Kinjo, K., Ikemiya, Y., and Takishita, S. 2003. "Blood Pressure Predicts Risk of Developing End-stage Renal Disease in Men and Women." American Heart Association 41 (6): 1341-5.

[53] Pinto-Sietsma, S. J., Navis, G., Janssen, W. M., de Zeeuw, D., Gans, R. O., de Jong, P. E., and PREVEND Study Group. 2003. "A Central Body Fat Distribution Is Related to Renal Function Impairment, Even in Lean Subjects." American Journal of Kidney Diseases 41 (4): 733-41.

[54] DiMatteo, M. R., Lepper, H. S., and Croghan, T. W. 2000. "Depression Is a Risk Factor for Noncompliance with Medical Treatment." Archive Internal Medicine 160 (14): 2101-7.

[55] Lew, S. Q., and Patel, S. S. 2007. "Psychosocial and Quality of Life Issues in Women with End-stage Renal Disease." Advances in Chronic Kidney Disease 14 (4): 358-63.

[56] Kimmel, P. L., Cukor, D., Cohen, S. D., and Peterson, R. A. 2007. "Depression in End-stage Renal Disease Patients: A Critical Review." Advances in Chronic Kidney Disease 14 (4): 328-34.

[57] Kimmel, P. L. 2001. "Psychosocial Factors in Dialysis Patients." Kidney Int. 59 (4): 1599-613. 